\title{
Anisograptus mojotorensis sp. nov. EN EL TREMADOCIANO TEMPRANO DEL NORTE ARGENTINO
}

\author{
Julio A. MONTEROS ${ }^{l}$ y M. Cristina MOYA ${ }^{1,2}$ \\ ${ }^{1}$ CI-UNSa - ${ }^{2}$ CONICET - Universidad Nacional de Salta, Facultad de Cien- \\ cias Naturales, Geología. Avda. Bolivia 5150-(4400) Salta, Argentina. E-mail: \\ julpaleo@unsa.edu.ar, moyacris@arnet.com.ar
}

Monteros, J. A. \& Moya, M. C. 2011. Anisograptus mojotorensis sp. nov. en el Tremadociano temprano del norte argentino. [Anisograptus mojotorensis sp. nov. in the early Tremadocian of northern Argentina.] Revista Española de Paleontología, 26 (1), 53-67. ISSN 0213-6937.

\begin{abstract}
Anisograptus mojotorensis sp. nov., a new species of triradiate anisograptid which has pseudo-quadriradiate symmetry in horizontal position is made known. The fossil material comes from the lower third of the Floresta Formation (Tremadocian), that copps out in the Mojotoro Range, southeastern edge of the Argentinian Eastern Cordillera. The Floresta Formation is a thick shale body, in which the Anisograptus, Adelograptus and Bryograptus kjerulfi Zones are developed. The new species was recorded in the Anisograptus Zone and defines the Anisograptus mojotorensis Subzone, which preceedes to the Anisograptus matanensis Subzone.

Well preserved material of $A$. mojotorensis sp. nov. includes more than one hundred specimens corresponding to proximal ends and complete and incomplete colonies of juvenile and mature forms. This material allows to describe in detail the proximal development of the new species, whose peculiar isograptid type have interest to the classification of the triradiate anisograptids showing a quadriradiate aspect in horizontal preservation. The pseudo-quadriradiate symmetry of the rhabdosomes of $A$. mojotorensis sp. nov. is adquired by the bifurcation of the first order stipe 1 inmediately after its origin. In most of the cases, the A. mojotorensis sp. nov. colonies are presented superimposed and horizontally conserved; in laterally preserved rhabdosomes, the three declined first order stipes are clearly observed, evidencing the typical triradiate pattern of the rhabdosome. Similarities and differences of A. mojotorensis sp. nov. with other species of Anisograptus are discussed, and the possible evolutive transition from the Staurograptus dichotomous group to the Anisograptus matanensis group is also proposed.

The A. mojotorensis Subzone can be correlated with the lower part of the A. matanensis Zone elsewhere, being a temporal equivalent to the upper part of the Iapetognatus conodont Zone that may reach the base of the Cordylodus angulatus conodont Zone.
\end{abstract}

Keywords: Graptolites, Anisograptidae, proximal development, taxonomical description, Ordovician, Tremadocian, Argentina.

\section{RESUMEN}

Se da a conocer Anisograptus mojotorensis sp. nov., una nueva especie de anisográptido trirradiado, que en posición horizontal tiene simetría pseudo-cuadrirradiada. El material fósil procede del tercio inferior de la Formación Floresta (Tremadociano), expuesta en la sierra de Mojotoro, extremo sudoriental de la Cordillera Oriental argentina. La Formación Floresta es un espeso cuerpo de lutita, en el que se desarrollan las zonas de Anisograptus, de Adelograptus y de Bryograptus kjerulfi. La nueva especie se registra en la Zona de Anisograptus y define la Subzona de Anisograptus mojotorensis, la cual precede a la Subzona de Anisograptus matanensis.

El material fósil de $A$. mojotorensis sp. nov. tiene buena conservación y comprende más de un centenar de especímenes correspondientes a partes proximales y a colonias completas e incompletas de formas juveniles y maduras. La buena condición del material permitió describir en detalle el desarrollo proximal de tipo isográptido de la nueva especie y realizar una diagnosis que facilitará la clasificación sistemática de anisográptidos trirradiados, los que conservados horizontalmente, tienen apariencia cuadrirradiada. La simetría pseudo-cuadrirradiada de los rabdosomas de $A$. mojotorensis sp. nov., se debe a que la estipe 1 de primer orden se bifurca inmediatamente después de su origen. En la mayoría de los casos, las colonias de A. mojotorensis sp. nov. se presentan superpuestas y conservadas horizontalmente; en especímenes conservados lateralmente, se observan claramente 
las tres estipes declinadas de primer orden, poniendo en evidencia el típico patrón trirradiado del rabdosoma. Se discuten similitudes y diferencias de A. mojotorensis sp. nov., con otras especies del género Anisograptus y se postula que la nueva especie podría ubicarse en la transición evolutiva entre el grupo de Staurograptus dichotomus y el grupo de $A$. matanensis.

La Subzona de A. mojotorensis se correlacionaría por un lado, con el intervalo más temprano de la Zona global de A. matanensis y por otro, con el estadio más tardío de la Zona de Iapetognatus, pudiendo alcanzar el lapso más temprano de la Zona de Cordylodus angulatus.

Palabras clave: Graptolitos, Anisograptidae, desarrollo proximal, descripción taxonómica, Ordovícico, Tremadociano, Argentina.

\section{INTRODUCCIÓN}

La familia Anisograptidae agrupa a los primeros graptolitos planctónicos "de aspecto dendroideo", desarrollo proximal cuadri, tri o birradiado, estipes integrados por autotecas y bitecas (estas últimas por lo general mal conservadas) y, en algunas especies, con presencia de disepimentos. El registro estratigráfico de los anisográptidos se inicia en los estadios más tempranos del Ordovícico y durante todo el Tremadociano constituyen, junto con los conodontes, los fósiles guía más importantes para establecer correlaciones intercontinentales.

Pese a la importancia bioestratigráfica de muchos anisográptidos, durante largo tiempo se discutió si la familia Anisograptidae debía vincularse con el orden Dendroidea (Bulman, 1950) o con el Graptoloidea (Fortey $\&$ Cooper, 1986) e inclusive, con un suborden especial: Graptodendroidina (Lin, 1981). Cooper et al. (1998) asignan la familia Anisograptidae al orden Graptoloidea y revisan la taxonomía y evolución de los anisográptidos cuadri y trirradiados. En este marco, redefinen los géneros Staurograptus Emmons, 1855 y Anisograptus Ruedemann, 1937. Interpretan que las especies relacionadas con estos géneros constituyen poblaciones con un amplio rango de variación morfológica. Consideran que el origen del género Anisograptus podría estar vinculado con Staurograptus (por supresión de una de las dicotomías iniciales de este último) o con una forma trirradiada de Rhabdinopora Eichwald, 1855. Reconocen en el género Anisograptus, las especies A. matanensis Ruedemann, 1937, A. ruedemanni Bulman, 1941, A. monseni Bulman, 1941 y A. isolatus Bulman, 1954. Establecen sinonimia entre A. matanensis y otras especies previamente definidas por Bulman (1941, 1954), como A. richardsoni, A. flexuosus, A. norvergicus y A. grandis. Incluyen dentro del género Anisograptus a Didymograptus primigenius Bulman, 1950, ?Bryograptus retroflexus Brogger, 1882 y ?Clonograptus (Staurograptus) heres Westergård, 1909 (fide Bulman, 1941, 1950).

Pese a la importante información brindada, Cooper et al. (1998) no trataron algunas especies de Anisograptus caracterizadas por rabdosomas pequeños, sutiles, que en vista horizontal presentan un aspecto cuadrirradiado, en apariencia similar al de Staurograptus, como A. guangdongensis Wang, Liu \& Zhou, 1979, A. delicatulus Cooper \& Stewart, 1979 y A. compactus Cooper \& Stewart, 1979. Las dos primeras fueron definidas casi simultáneamente en China y en Australia y su situación taxonómica, de probable sinonimia, aún no fue debidamente aclarada (fide Cooper \& Stewart, 1979; Wang et al., 1979; Erdtmann \& Bostford, 1986; Wang \& Erdtmann, 1986).

El objetivo del presente trabajo es describir e ilustrar Anisograptus mojotorensis sp. nov., un anisográptido de colonias delicadas, que a pesar de tener el patrón trirradiado típico del género, cuando se conserva en posición horizontal, tiene simetría pseudo-cuadrirradiada. La nueva especie presenta diferencias respecto a las incluidas en Anisograptus por Cooper et al. (1998), aunque guarda estrechas afinidades con las especies $A$. guangdongensis y $A$. delicatulus arriba mencionadas, cuyos desarrollos proximales son prácticamente desconocidos. El material fósil aquí analizado fue aislado de la roca portadora, empleando una nueva técnica físico-química (Monteros, 2005; Monteros et al., 2011), que optimizó la observación de las colonias y permitió describir, por primera vez, los detalles del extremo proximal de representantes de un grupo caracterizado por la sutileza y el pequeño tamaño de los rabdosomas. El diseño pseudo-cuadrirradiado que presenta $A$. mojotorensis sp. nov. en colonias conservadas horizontalmente, unido al valor de algunos datos biométricos de la especie, sugieren que ésta podría ubicarse en la transición evolutiva entre el patrón cuadrirradiado que caracteriza a Staurograptus y el evidente diseño trirradiado que en vistas horizontales presentan las especies del grupo de A. matanensis. En consecuencia, el material aquí descrito e ilustrado, podría brindar nuevos elementos de juicio para discutir el origen de Anisograptus a partir de Staurograptus. Por tanto, se espera que la presente contribución aporte datos para futuras comparaciones con especies afines, sus variedades astogenéticas $\mathrm{y} / \mathrm{o}$ intraespecíficas.

A. mojotorensis sp. nov. es un miembro de la Zona de Anisograptus reconocida en la sierra de Mojotoro, Cordillera Oriental argentina, donde define la subzona homónima, la cual precede a la Subzona de A. matanensis (Monteros, 2005; Monteros \& Moya, 2006; Moya \& Monteros, 2011). 


\section{PROCEDENCIA DEL MATERIAL ESTUDIADO}

Anisograptus mojotorensis sp. nov. procede del tercio inferior de la Formación Floresta, un litosomo de lutita depositado entre finales del Tremadociano temprano y mediados del Tremadociano tardío (Monteros \& Moya, 2006; Moya \& Monteros, 2011). El material fósil procede de la sección tipo de la Formación Floresta, ubicada al sudeste de la ciudad de Salta, en el flanco occidental de la sierra de Mojotoro, extremo sudoriental de la Cordillera Oriental argentina (Fig. 1).

La sierra de Mojotoro es una típica estructura anticlinal del antepaís andino y expone una de las columnas integradas más completas del Paleozoico inferior de América del Sur. El basamento estratigráfico o núcleo del anticlinal está compuesto por tres unidades marcadamente distintas de rocas clásticas, plegadas y afectadas por metamorfismo de bajo a muy bajo grado, asignadas al Ediacárico-Cámbrico inferior (Moya, 1998; Aparicio González et al., 2010).

A través de una discordancia angular de primer orden (Discordancia Tilcara), las rocas del basamento subyacen a una cobertura paleozoica inferior menos deformada. Dicha cobertura es clástica y está representada por el Grupo Mesón (Cámbrico medio) y el Grupo Santa Victoria (Furongiano-Ordovícico superior), ambos, separados a su vez por una discordancia erosiva (Discordancia Iruya).

El Grupo Mesón está constituido por areniscas limpias y limolitas bioturbadas y su depósito fue vinculado con ambientes dominados por mareas (sub, inter y supramareales) (Moya, 1998). El Grupo Santa Victoria está integrado por cuerpos de arenisca cuarzosa y de lutita fosilífera que alternan entre sí (Fig. 1e), los que fueron depositados en distintos subambientes de plataforma marina y representan sucesivos episodios de transgresión-regresión. Estas unidades comprenden de base a tope, las formaciones La Pedrera (areniscas), San José (lutitas), Caldera (areniscas), Floresta (lutitas), Áspero (areniscas), San Bernardo (lutitas), Mojotoro (areniscas) y Santa Gertrudis (lutitas). Las cinco unidades más antiguas son de edad tremadociana, la Formación San Bernardo registra el pasaje TremadocianFloiano, la Formación Mojotoro correspondería al lapso Dapingiano-Darriwiliano y la Formación Santa Gertrudis, al Darriwiliano superior-Sandbiano (Harrington, 1957; Albanesi et al., 2007; Moya, 2008; Carlorosi et al., 2011).

La columna estratigráfica de la sierra de Mojotoro continúa con los depósitos clásticos y carbonáticos del Grupo Salta (Cretácico-Paleógeno), que cubren discordantemente a distintas unidades del Grupo Santa Victoria y subyacen también en discordancia, a las acumulaciones continentales del Grupo Orán (Neógeno).

El material asignado a Anisograptus mojotorensis sp. nov. procede del intervalo pelítico inferior de la Formación Floresta y su registro precede a la primera aparición de $A$. matanensis, que ocurre en el tramo superior de este intervalo pelítico (Fig. 1e). A estos depósitos suceden dos episodios de somerización, el más joven de los cuales está representado por una conspicua facies de arenisca cuarzocalcárea y coquina, portadora de abundante fauna de la Zona de Kainella meridionalis (Fig. 1e).

Las rocas portadoras de A. mojotorensis sp. nov. corresponden a lutitas arcillosas de colores gris verdoso oscuro, pardo verdoso y pardo amarillento, asignadas a un ambiente de plataforma intermedia a distal (Moya, 1998). Los niveles fosilíferos son escasos y de espesores milimétricos. Éstos, sin embargo, constituyen verdaderos "tapices graptolíticos", debido a la cantidad y calidad del material fósil que contienen.

Los depósitos con A. mojotorensis sp. nov. coexisten con Triograptus osloensis, Kiaerograptus? sp. y con una importante asociación de trilobites tremadocianos (Malanca,1996; Aris \& Malanca, 2005), entre cuyos integrantes se destaca la asociación de Apatokephalus exiguus-Conophrys sulcata, la cual fue propuesta por Monteros (2005) para identificar la biozona homónima; de esta manera, existe una equivalencia temporal entre la Subzona de Anisograptus mojotorensis y la parte baja de la de A. matanensis, con la Zona de Apatokephalus exiguus-Conophrys sulcata.

\section{SISTEMÁTICA PALEONTOLÓGICA}

\author{
Clase GRAPTOLITHINA Bronn, 1849 \\ (nom. transl. Elles, 1922) \\ Orden GRAPTOLOIDEA Lapworth in \\ Hopkinson \& Lapworth, 1875 \\ Familia Anisograptidae Bulman, 1950
}

\section{Género Anisograptus Ruedemann, 1937}

Especie tipo: Anisograptus matanensis Ruedemann, 1937, por designación original.

Diagnosis (Cooper et al., 1998): Triradiate anisograptid with horizontal to subhorizontal rhabdosome form; spacing of dichotomies highly variable; number of stipes unrestricted; development based on dicalycal thecae $t 1^{2}$ and $t 1^{3}$.

Anisográptido trirradiado con rabdosoma de forma horizontal a subhorizontal; espaciamiento de dicotomías altamente variable; ilimitado número de estipes; desarrollo basado en las tecas dicálicas $t 1^{2}$ y $1^{3}$.

\section{Anisograptus mojotorensis sp. nov.} Figs. 2, 3, 4, 5

v 1994 Anisograptus sp.; Moya et al., p. 96, lám. 2, fig. 3.

v 1994 Staurograptus sp. cf. dichotomus Emmons; Moya et al., p. 96, lám. 2, fig. 5.

v 1999 Anisograptus delicatulus Cooper y Stewart; Monteros, p. 50-51, sólo cita. 


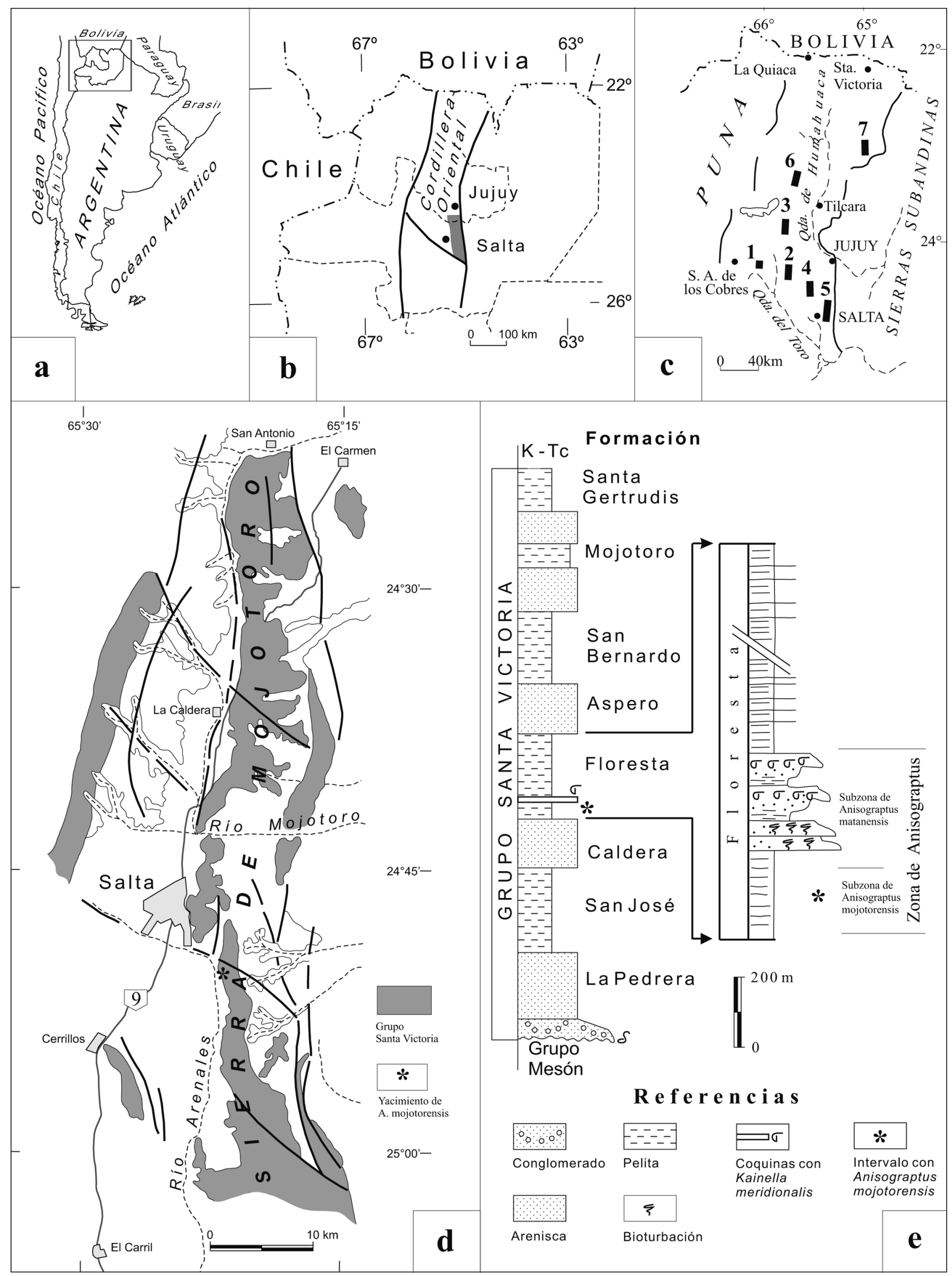


Localidad tipo: Villa Floresta (244' $00^{\prime \prime}$ Lat. S; 65²2'09" Long. O), en el este de la ciudad de Salta, flanco occidental de la sierra de Mojotoro.

Estrato tipo: Intervalo pelítico inferior de la Formación Floresta, en el perfil tipo de la unidad, al sudoeste de la ciudad de Salta.

Derivatio nominis: En referencia a la sierra de Mojotoro, área de procedencia del material fósil descrito.

Material estudiado: El material recolectado incluye más de un centenar de especímenes; está depositado en la cátedra de $\mathrm{Pa}-$ leontología General de la Universidad Nacional de Salta, bajo la sigla CNS-I 139/795. Los restos presentan buena a muy buena conservación; en la gran mayoría de los especímenes se conservó la materia carbonosa, mientras que otros se presentan como impresiones ferruginosas. Los restos corresponden a partes proximales y a colonias completas e incompletas de formas maduras y juveniles. Las colonias se presentan superpuestas, sin aparente deformación; predominan las conservadas horizontalmente.

Holotipo: CNS-I 139/795 (5), Fig. 5b.

Paratipo: CNS-I 139/795 (9), Fig. 5e.

Diagnosis: Triradiate rhabdosome, though generally with pseudo-quadriradiate symmetry; delicate, with horizontal form and variable size (8 to $20 \mathrm{~mm}$ diameter). The proximal development is isograptid, with right-handed origin and dextral growth of the first dicalycal thecae ( $\left.h 1^{2}\right)$. Consisting of few thin stipes (0.30-0.47 mm dorso-ventral width); variable branching pattern, with very short first and second order stipes (first order stipe 1 is always the shortest). Markedly asymmetrical proximal development in lateral view. Long and thin sicula with blunt ápex (average length $1.5 \mathrm{~mm}$ ), probably due to loss of part of the prosicula. Thin, straight to gently curved autothecae, with slightly denticulate thecal apertures; with bithecas. The thecal density is 10-12 in $10 \mathrm{~mm}$.

Rabdosoma trirradiado, aunque generalmente con simetría pseudocuadrirradiada; delicado, de forma horizontal y tamaño variable (diámetro de 8 a $20 \mathrm{~mm}$ ). El desarrollo proximal es isográptido con origen derecho y crecimiento dextral de la primera teca dicálica $\left(\mathrm{t} 1^{2}\right)$. Compuesto de pocos estipes delgados (0,30-0,47 mm de anchura dorso-ventral); patrón de ramificación variable, con estipes de primero y segundo orden muy cortos (el estipe 1 de primer orden es siempre el más corto). Parte proximal marcadamente asimétrica en vista lateral. Sícula larga y delgada sin ápice pronunciado $(1,5 \mathrm{~mm}$ de longitud promedio), probablemente por pérdida de parte de la prosícula. Autotecas delgadas, rectas a suavemente curvadas, con aperturas ligeramente denticuladas; con bitecas. La densidad tecal es de 10-12 tecas en $10 \mathrm{~mm}$.

\section{Descripción}

Desarrollo proximal: Los especímenes analizados presentan un desarrollo proximal que ratifica el modelo general propuesto por Maletz (1992) para anisográptidos trirradiados. Es decir, corresponden al tipo isográptido, con una teca unicálica ( $\mathrm{t} 1^{1}$ ) y dos tecas dicálicas sucesivas ( $\mathrm{t} 1^{2}$ y $\mathrm{t}^{3}$ ); estas últimas se disponen sobre un mismo lado del rabdosoma. En consecuencia, la parte proximal es marcadamente asimétrica, con dos estipes de primer orden desarrollados sobre un lado del rabdosoma y el otro estipe sobre el lado opuesto (Figs. 2a-2d, 3a, 3b, 3e, 3f, 4a).

La sícula se observa en especímenes conservados lateralmente $y$ en algunas formas horizontales (Figs. 2a-2d, 3a, 3b, 3e, 3f, $3 \mathrm{~g}, 4 \mathrm{a}-4 \mathrm{~d} ; 5 \mathrm{a}, 5 \mathrm{~b}, 5 \mathrm{~d})$. Es larga y delgada, con ápice obtuso y redondeado, probablemente por pérdida de parte de la prosícula (Fig. 2a, 2c, 2d); las anchuras apical y apertural son ligeramente distintas. Presenta bordes rectos desde el ápice hasta el sector medio-inferior, donde se curva hacia el lado dorsal hasta alcanzar el borde apertural, el cual presenta un pequeño rutellum; en ningún ejemplar se observó nema. Presenta una longitud de 1,4-1,6 $\mathrm{mm}$ y un ancho apertural de 0,16-0,30 $\mathrm{mm}$. Una biteca sicular mal conservada se observó en uno de los especímenes (Fig. 4a).

La teca $1^{1}$ nace a 0,32-0,46 $\mathrm{mm}$ desde la metasícula y se desarrolla adosada al margen ventral de la sícula, en forma recta a lo largo de 0,4-0,7 mm. Luego diverge hacia fuera, con un ángulo que oscila entre $70^{\circ}$ y $85^{\circ}$ respecto al eje sicular. La pared subapertural tiene una longitud promedio de $1 \mathrm{~mm}$ y la apertura tecal una anchura de $0,35 \mathrm{~mm}$. La teca $\mathrm{t} 1^{1}$ origina la primera teca dicálica: la t $1^{2}$ (Figs. 2a-2d, 3a, 3b, 3e-3g, 4a-4d, 5b).

La teca $1^{2}$ nace de la $\mathrm{t} 1^{1}$, próxima al punto de flexión de ésta, en el lado derecho de la sícula, y crece dextralmente cruzando oblicuamente sobre esta última. En las proximidades de la apertura sicular se desvía hacia abajo, desarrollando el estipe 2 de primer orden. La teca $t 1^{2}$ tiene una longitud promedio de $1,5 \mathrm{~mm}$ y da origen a la teca $1^{3}$ y a la t $2^{1}$ (Figs. $2 \mathrm{a}-2 \mathrm{~d}, 3 \mathrm{a}, 3 \mathrm{~b}$, 3e, 4a, 4c, 4d, 4f, 5b).

La teca $1^{3}$, con origen derecho y crecimiento dextral, nace próxima a la apertura sicular, constituyendo la segunda teca dicálica sucesiva, a partir de la cual se desarrolla el estipe 3 de primer orden (Figs. 2a-2d, 3a, 3b, 3e-3g, 4a-4d, 5b).

La teca $2^{1}$ se origina sobre el lado izquierdo de la $1^{2}$ y crece a lo largo del margen dorsal de la $t 1^{1}$ para desarrollar el estipe 1 de primer orden. La teca t $2^{1}$ daría origen a la dicálica t $3^{1}$, a partir de la cual surge la primera dicotomía distal. Ésta es la que

Figura 1. a, b. Ubicación de la Cordillera Oriental argentina y de la Sierra de Mojotoro. c. Ubicación de clásicas secciones tremadocianas en la Cordillera Oriental argentina: 1, Angosto La Quesera. 2, Cerros de Pascha. 3, Angosto El Moreno. 4, Cordón de Lesser. 5, Sierra de Mojotoro. 6, Sierra de Cajas. 7, Sierra de Zenta. d. Mapa de afloramientos del Grupo Santa Victoria en la Sierra de Mojotoro y en el Cordón de Lesser (sensu Moya, 1998). e. Columna estratigráfica del Grupo Santa Victoria en la Sierra de Mojotoro, con detalle de la Zona de Anisograptus en la Formación Floresta.

$\boldsymbol{a}, \boldsymbol{b}$. Location of the Argentinian Eastern Cordillera and Mojotoro Range. c. Location of classic Tremadocian sections in the Argentinian Eastern Cordillera: 1, Angosto La Quesera. 2, Pascha Hills. 3, Angosto El Moreno. 4, Lesser Range. 5, Mojotoro Range. 6, Cajas Range. 7, Zenta Range. d. Map of the Santa Victoria Group outcroppings in Mojotoro and Lesser Ranges (sensu Moya, 1998). e. Stratigraphic column of the Santa Victoria Group in Mojotoro Range, with detail of the Anisograptus Zone in the Floresta Formation. 


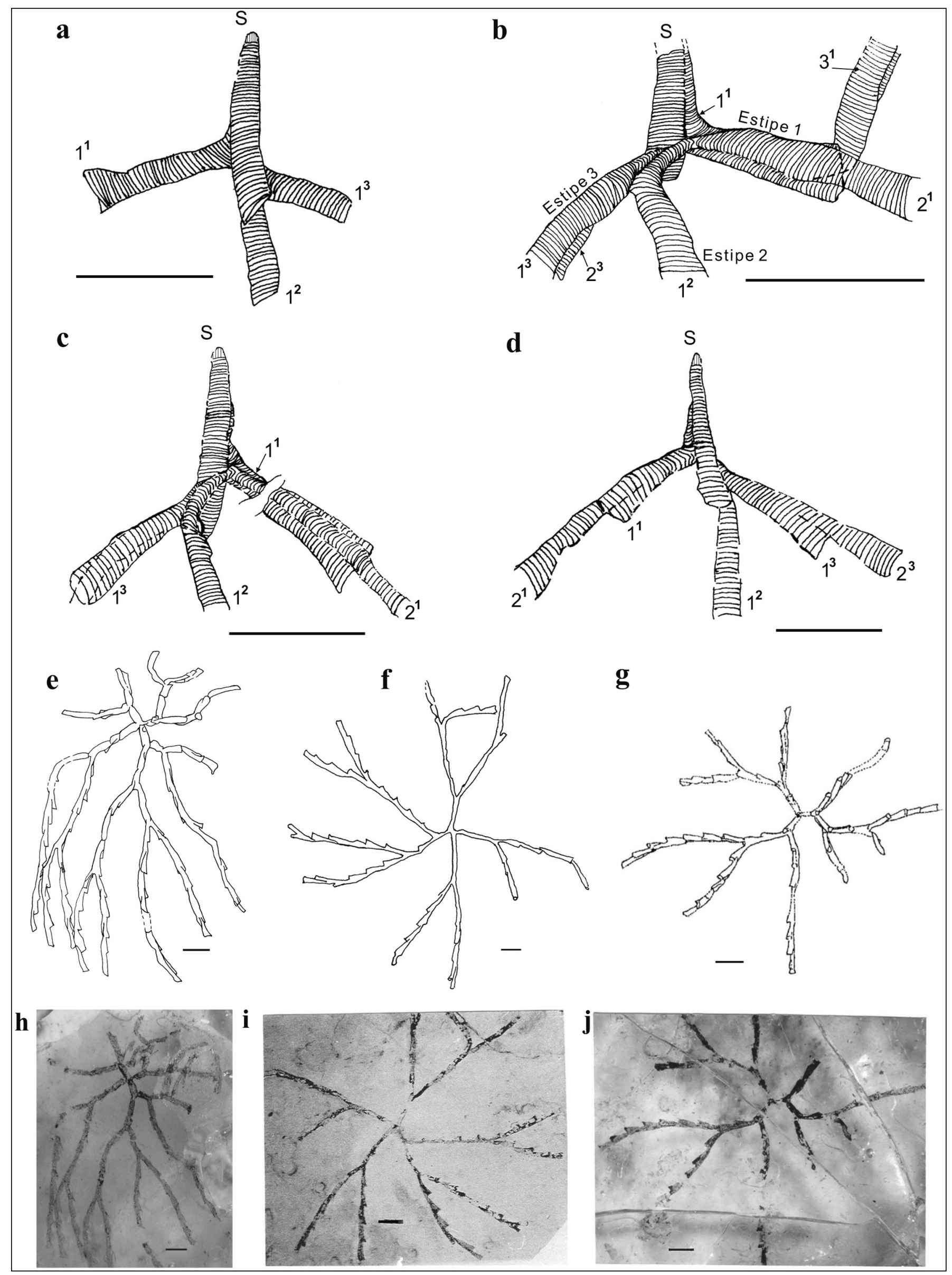


en vista horizontal aparenta un cuarto estipe de primer orden, el cual induce a la errónea interpretación de un rabdosoma cuadrirradiado que, en algunos casos (Moya et al., 1994), fue referido al género Staurograptus (Figs. 2b-2d, 3a, 3b, 3e, 3f, 4a-4d, 5b, 5d).

Morfología general de las colonias: El rabdosoma es de tamaño pequeño, con aspecto delicado, muy característico de la especie. Su diámetro oscila entre 8 y $20 \mathrm{~mm}$, según se trate de formas juveniles o maduras.

En el material analizado, la naturaleza trirradiada del rabdosoma es evidente en especímenes declinados conservados lateralmente, en los que se observan claramente los tres estipes de primer orden (Figs. 2a-2d, 3a, 3b, 3e, 3f, 4a, 4c, 4d, 5b). Sin embargo, un aparente desarrollo cuadrirradiado caracteriza a la gran mayoría de las colonias, dado que el hábito de conservación dominante es horizontal. En esta vista, la apariencia cuadrirradiada responde a que el estipe 1 de primer orden se bifurca inmediatamente después de su origen.

Los estipes son muy delgados, con una anchura dorso-ventral de 0,30-0,47 $\mathrm{mm}$ y anchura lateral de $0,30-0,35 \mathrm{~mm}$. La longitud de los estipes es marcadamente variable: los estipes de primer orden varían entre 1,0 y $2,9 \mathrm{~mm}$; los de segundo orden entre 1,9 y 4,7 mm, y los de tercer orden entre 3,2 y 5,9 mm. Las colonias maduras, con estipes de cuarto orden, presentan una distribución discoidal regular; éstas desarrollan hasta 16 estipes terminales. La ramificación de todos los estipes es dicotómica. Los ángulos de bifurcación de los estipes de primero, segundo y tercer orden son: $45^{\circ}-70^{\circ}, 42^{\circ}-90^{\circ}$ y $40^{\circ}-63^{\circ}$, respectivamente.

Las autotecas son rectas a suavemente curvadas, delgadas, con longitudes de 1,0-1,75 mm y aperturas ligeramente denticuladas, cuyo ancho es de 0,30-0,47 mm. La inclinación tecal es de $10^{\circ}-15^{\circ}$ y el solapamiento representa poco menos de la mitad de su longitud ventral. En algunos especímenes se observaron muy pocas bitecas dispuestas irregularmente a lo largo de los estipes (Fig. 4c-4e, 4h). El espaciamiento tecal es de 10-12 tecas en $10 \mathrm{~mm}$.

Observaciones: El desarrollo proximal en anisográptidos fue objeto de importantes estudios que fueron revisados y discutidos por Maletz (1992) y Cooper et al. (1998). En estos trabajos se propone un modelo general para explicar la evolución cuadri y trirradiada en la familia Anisograptidae. El primer autor destaca que el problema taxonómico de los anisográptidos reside, principalmente, en la deficiente conservación del material fósil disponible; en consecuencia, resulta difícil documentar el desarrollo proximal y distal de las colonias, parámetros fundamentales para su diagnosis.

Las consideraciones precedentes son particularmente aplicables a muchas especies de Staurograptus y Anisograptus, dada la naturaleza delicada de las colonias, aspecto que incide en el potencial de conservación del material fósil y por ende, en la atribución objetiva a uno u otro de los géneros mencionados.

Un clásico ejemplo de lo antedicho lo constituye la especie Staurograptus diffissus Harris \& Keble, 1928, definida en Victoria (Australia). Basándose en nuevas colecciones, Cooper \& Stewart (1979) definen A. delicatulus y A. compactus y asignan a cada una de ellas, el holotipo y uno de los paratipos de "S. diffissus", respectivamente. Destacan que en las nuevas especies, uno de los estipes de primer orden se bifurca inmediatamente después de su origen, presentando en vista horizontal un aspecto cuadrirradiado en apariencia similar al de Staurograptus, carácter que podría inducir a una asignación genérica errónea. Precisamente, éste fue el caso de un espécimen de $A$. mojotorensis sp. nov. conservado en posición horizontal, con escasa definición de su parte proximal; éste fue asignado a Staurograptus cf. dichotomus por Moya et al. (1994; Lám. 2, Fig. 5), por la sutileza y aspecto cuadrirradiado del rabdosoma y una frecuencia tecal similar al de dicha especie. Lo antedicho marca la importancia del material fósil posteriormente recuperado y aquí discutido, en tanto y cuanto su calidad permitió describir la parte proximal de colonias muy sutiles que en vista lateral y horizontal (Figs. 2, 3, 4 y 5), demuestran fehacientemente un desarrollo proximal trirradiado, propio del género Anisograptus.

Figura 2. Desarrollo proximal de Anisograptus mojotorensis sp. nov. 139/795 (1-4, 9), Villa Floresta. a (1), d (4): Especímenes en vista lateral-anversa con desarrollo dextral, mostrando las tecas primarias. b (2), c (3): Especímenes en vista lateral-reversa con desarrollo dextral, mostrando las tecas $1^{1}, 1^{2}$ (primera dicálica), $1^{3}$ (segunda dicálica), $2^{1}$ y $3^{1}$ (primera dicálica distal). Además se observan los tres estipes de primer orden. f (9): Desarrollo proximal trirradiado, con tres estipes primarios, aunque con aparente desarrollo cuadrirradiado que caracteriza a la mayoría de las colonias con conservación horizontal. e: Staurograptus sp. aff. S. dichotomus Emmons, 1855, 140/806 (1), Finca Miraflores. Rabdosoma maduro cuadrirradiado característico del género, formado por cuatro estipes primarios. g: Anisograptus matanensis Ruedemann, 1937, 134/792 (6), Autódromo. Colonia madura con desarrollo proximal trirradiado clásico del género. $\mathbf{h}, \mathbf{i}$, j: Fotos correspondientes a los especímenes e, f y g respectivamente. Escala de las barras $1 \mathrm{~mm}$.

Proximal development of Anisograptus mojotorensis sp. nov. 139/795 (1-4, 9), Villa Floresta. a (1), d (4): Specimens in lateral-anverse view with dextral condition, showing the primary thecae. $\boldsymbol{b}$ (2), c (3): Specimens in lateral-reverse view with dextral condition, showing the thecae $1^{1}, 1^{2}$ (first dicalycal), $1^{3}$ (second dicalycal), $2^{1}$ and $3^{1}$ (first distal dicalycal). The three first order stipes are also observed. $f(9)$ : Triradiate proximal development with three primary stipes, although with apparent cuadriradiate development characteristic of most horizontally conserved colonies. $\boldsymbol{e}$ : Staurograptus $s p$. aff. S. dichotomus Emmons, 1855, 140/806 (1), Finca Miraflores. Mature quadriradiate rhabdosome characteristic of the genus, formed by four primary stipes. g: Anisograptus matanensis Ruedemann, 1937, 134/792 (6), Autódromo. Mature colony with trirradiate proximal development classic of the genus. $\boldsymbol{h}, \boldsymbol{i}, \boldsymbol{j}$ : Pictures corresponding to the specimens $\boldsymbol{e}, \boldsymbol{f}, \boldsymbol{g}$, respectively. Bar scale $1 \mathrm{~mm}$. 

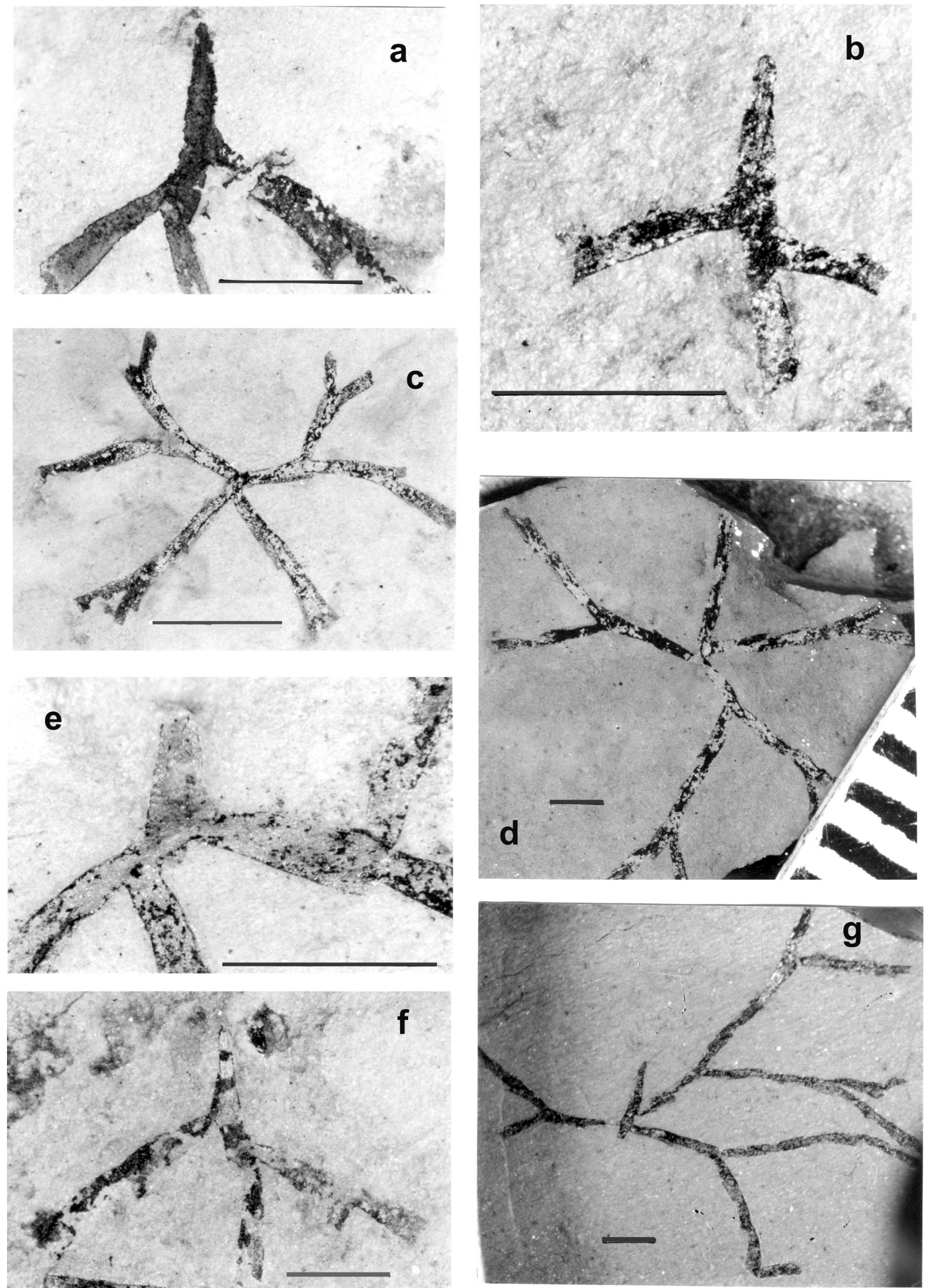
Ahora bien, A. mojotorensis sp. nov. es bastante distinta de las especies incluidas en el género Anisograptus por Cooper et al. (1998). Estos autores redefinen A. matanensis y agrupan en ésta, distintas especies y subespecies previamente definidas por Bulman (1941, 1950, 1954), a las que consideran como variantes intraespecíficas. Así redefinida, A. matanensis presenta estipes con anchura dorso-ventral de $0,9-1,6 \mathrm{~mm}$ y anchura lateral de $0,5-0,6 \mathrm{~mm}, 9,0-10,5$ tecas en $10 \mathrm{~mm}$, sícula cónica (1,2-1,4 mm de longitud), con ápice agudo, nema y amplia apertura sicular. A. mojotorensis sp. nov. es una forma mucho más delicada, cuyos estipes tienen anchura dorso-ventral de 0,30-0,45 $\mathrm{mm}$ y anchura lateral de $0,30-0,35$, mayor contenido tecal (10-12 tecas en 10 $\mathrm{mm}$ ), sícula más larga y delgada (1,4-1,6 mm de longitud), sin ápice pronunciado (nema no observado) y anchuras apical y apertural ligeramente distintas. Por otro lado, A. mojotorensis sp. nov. se distingue de A. ruedemanni, A. monseni y $A$. isolatus por ser estas últimas formas notablemente más robustas y presentar sícula más larga $(1,8-2 \mathrm{~mm})$.

En contraposición, A. mojotorensis sp. nov. presenta semejanzas con otros anisográptidos trirradiados de rabdosomas pequeños y delicados que en vista horizontal presentan simetría pseudocuadrirradiada como A. compactus, A. delicatulus y A. guangdongensis.

A. compactus se distingue de $A$. mojotorensis sp. nov., por presentar sícula más corta $(0,8 \mathrm{~mm}$ de longitud), patrón de ramificación más denso (36 estipes terminales) y mayor contenido tecal (18 tecas en $10 \mathrm{~mm}$ ).

Por otro lado, A. delicatulus y A. mojotorensis sp. nov. tienen patrones de ramificación similares, siendo éstos más abiertos (16 estipes terminales). Sin embargo, en $\mathrm{A}$. delicatulus el contenido tecal es sustancialmente mayor (17-19 en $10 \mathrm{~mm}$ ), el diámetro del rabdosoma es menor (máximo $13 \mathrm{~mm}$ ) y la sícula es ligeramente más corta y de diseño cuneiforme. En A. mojotorensis sp. nov. la sícula tiene el extremo apical romo, con una anchura ligeramente menor que la del extremo apertural.

A. compactus y A. delicatulus integran la asociación de graptolitos que define la Biozona de Rhabdinopora scitula-Anisograptus en Victoria, Australia (Lancefieldiano 1a, Cooper, 1999). A. compactus fue identificada también en el Tremadociano del oeste de Terranova por Erdtmann \& Botsford (1986), quienes consideran que esta especie es una variedad infraespecífica de $A$. richardsoni $(=A$. matanensis, sensu Cooper et al., 1998). Por su parte, A. delicatulus fue mencionada también, en el Tremadociano de México (Sour \& Buitrón, 1987) y del sudeste de China (Chen, 1985; Li et al., 1985; Xiao \& Chen, 1993). En todos los casos, los rabdosomas son pequeños y sutiles, aunque parámetros como espaciamiento tecal y longitud de la sícula no son indicados o difieren de los asignados originalmente a $A$. delicatulus. Así, en el material mexicano, la sícula no fue observada, aunque el contenido tecal es similar al de la especie australiana. En el material chino, la longitud de la sícula es variable, 0,8 mm (Li et al., 1985), 1,2 mm (Xiao $\&$ Chen, 1993), 1,0-1,5 mm (Chen, 1985); el último autor no da valores de espaciamiento tecal y el mencionado por Li et al. (1985) y Xiao \& Chen (1993) es sustancialmente menor que el del material australiano (10-12,5 tecas en $10 \mathrm{~mm}$ ). Resulta interesante señalar que el material chino asignado a $A$. delicatulus tiene, en muchos casos, mayor afinidad con $A$. mojotorensis sp. nov. que con la especie australiana a la que fue referido. Por otro lado, Wright et al. (1994) identificaron con nomenclatura abierta $A$. sp. cf. delicatulus, un espécimen procedente del Tremadociano de Mt Patriarch (Nueva Zelanda), sólo por presentar sícula más corta (1 $\mathrm{mm}$ de longitud) que la especie australiana.

De todo el material referido a $A$. delicatulus señalado precedentemente, el asignado a dicha especie por Xiao \& Chen (1993), es el que guarda mayores afinidades con $A$. mojotorensis sp. nov. Este hecho, unido al concepto que las especies de Anisograptus integran poblaciones con un amplio rango de variación morfológica (fide Cooper et al., 1998), indujo a que Monteros (1999) identificara como $A$. delicatulus, los especímenes primeramente encontrados en la sierra de Mojotoro y que aquí son identificados como $A$. mojotorensis sp. nov. La reasignación de dichos especímenes responde a que ellos presentan parámetros biométricos idénticos a los del material posteriormente recolectado y que permitió definir A. mojotorensis sp. nov.

Ahora bien, A. delicatulus no fue revisada por Cooper et al. (1998) y su situación taxonómica aún no fue debidamente aclarada; incluso, algunos autores consideran que dicha especie sería un sinónimo de A. guangdongensis (Chen, 1985), la cual, según Wang \& Erdtmann (1986, pág. 16), habría sido publicada poco antes que $A$. delica-

Figura 3. Especímenes de Anisograptus mojotorensis sp. nov. mostrando diferentes aspectos conservacionales. 139/795 (1, 2, 3, 4, 7, 11, 12), Villa Floresta. a (3), f (4): Especímenes juveniles conservados lateralmente mostrando las tecas primarias. b (1): Extremo proximal. c (12), d (11): Rabdosomas juveniles conservados discoidalmente mostrando aspecto pseudo-cuadrirradiado. e (2): Parte proximal de rabdosoma maduro en vista reversa y con desarrollo dextral, con tres estipes de primer orden y uno de segundo orden. g (7): Espécimen maduro mostrando la sícula con los tres estipes de primer orden. Escala de las barras $1 \mathrm{~mm}$.

Anisograptus mojotorensis sp. nov. specimens showing different preservation aspects. 139/795 (1, 2, 3, 4, 7, 11, 12), Villa Floresta. a (3), $\boldsymbol{f}(4)$ : Juvenile specimens laterally preserved showing the primary thecae. $\boldsymbol{b}$ (1): Proximal development. $\boldsymbol{c}$ (12), d (11): Juvenile rhabdosomes discoidally preserved, showing pseudo-quadriradiate aspect. e (2): Mature rhabdosome showing proximal development with three first order stipes and one second order stipe. $\boldsymbol{g}$ (7): Mature specimen showing the sicula with three first order stipes. Bar scale $1 \mathrm{~mm}$. 

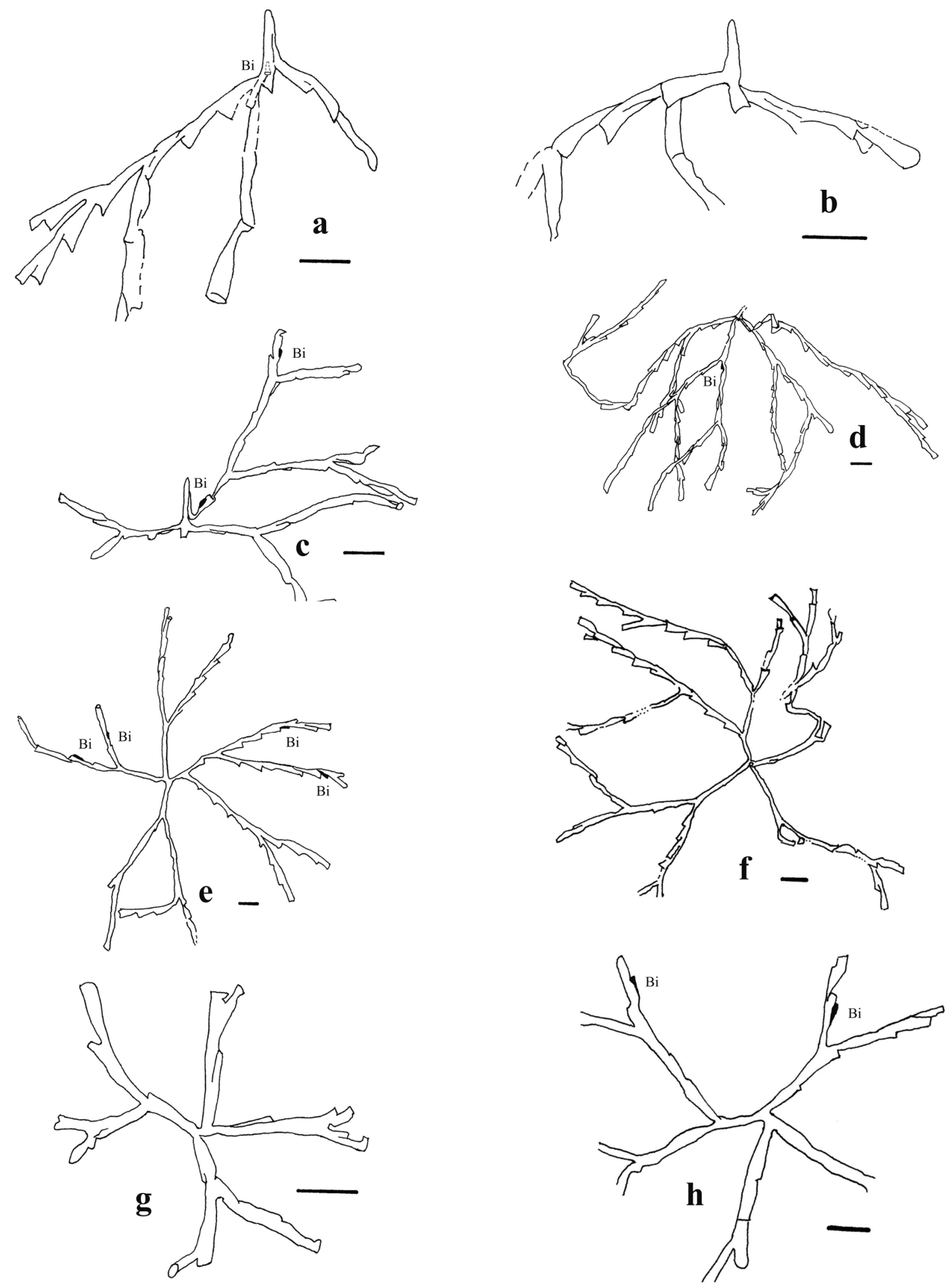
tulus. En otras palabras, quedó planteado un problema de probable sinonimia y por ende, de prioridad nomenclatural aún no resuelto; en adición, A. guangdongensis sólo fue mencionada en sucesiones del Tremadociano de China (Wang et al., 1979; Li et al., 1985; Xiao \& Chen, 1993). Los parámetros señalados por estos autores sugieren que dicha especie también guarda afinidades con $A$. mojotorensis sp. nov. distinguiéndose de ésta por un diámetro menor del rabdosoma, estipes de primer orden más cortos y sícula más pequeña (1,0-1,2 mm de longitud).

Está claro que A. mojotorensis sp. nov., A. delicatulus y $A$. guangdongensis integran un grupo de anisográptidos trirradiados con rasgos morfológicos distintivos, aunque a diferencia del material argentino, el desarrollo proximal de las especies china y australiana es prácticamente desconocido.

Si bien A. mojotorensis sp. nov. es indiscutiblemente un anisográptido trirradiado, su apariencia similar a la de Staurograptus en especímenes conservados horizontalmente, es igualmente innegable, no sólo por su simetría pseudocuadrirradiada, sino por la sutileza de las colonias, anchura de los estipes y forma, longitud, anchura e inclinación de las tecas. Parece incluso que A. mojotorensis podría ser una forma intermedia entre $S$. dichotomus Emmons, 1855 y A. matanensis. Aunque hoy esta opinión es una conjetura, no se descarta que el material aquí descrito e ilustrado, pueda brindar nuevos elementos de juicio en favor de la interpretación de Maletz (1992), respecto al origen del género Anisograptus a partir de Staurograptus.

\section{CONSIDERACIONES BIOESTRATIGRÁFICAS}

Anisograptus es uno de los géneros más representativos del Tremadociano inferior tardío; su presencia se registra en las dos últimas biozonas internacionales propuestas para este lapso: zonas de Anisograptus matanensis y de Rhabdinopora flabelliformis anglica (Cooper et al., 1998; Cooper, 1999).

En América del Sur, el género Anisograptus fue citado por primera vez en Argentina, en la sucesión tremadociana de Río Volcancito, en el Sistema de Famatina (Turner, 1960). Esta información fue posteriormente ampliada por Aceñolaza \& Durand (1984) y más recientemente analizada por Gutiérrez-Marco \& Esteban (2005). Los datos de Fa- matina fueron por mucho tiempo, los únicos conocidos de Anisograptus en América del Sur; a partir de Moya et al. (1994), el género también se conoce en distintas áreas de la Cordillera Oriental argentina. En esta región, Anisograptus define la biozona homónima reconocida en el tercio inferior de la Formación Floresta de la sierra de Mojotoro y en uno de sus equivalentes faciales y temporales, la Formación Saladillo, expuesta en las áreas de Pascha, sierra de Cajas, Angosto del Moreno y Angosto de la Quesera (Fig. 1c) (fide Monteros \& Moya, 2005; Ortega \& Albanesi, 2005).

A pesar de la distribución geográfica relativamente importante de Anisograptus en la Cordillera Oriental, la presencia de A. mojotorensis sp. nov. sólo fue registrada en la Formación Floresta de la sierra de Mojotoro; en esta área, la nueva especie constituye el graptolito trirradiado más antiguo y su aparición precede al registro de $\mathrm{A}$. $\mathrm{ma}$ tanensis. Ambas especies nominan las dos subzonas que integran la Zona de Anisograptus; ésta se extiende a través de dos ciclos de inundación-somerización en el tramo inferior de la Formación Floresta: 1) La Subzona de A. mojotorensis se desarrolla enteramente dentro del ciclo más antiguo, el que culmina con capas bioturbadas y una superficie de omisión (Fig. 1e). 2) La Subzona de A. matanensis se inicia en el tramo superior de las pelitas del ciclo anterior y persiste a través del siguiente ciclo, el que culmina con un intervalo caracterizado por abundantes capas de coquina, con fauna de la Zona de Kainella meridionalis (Fig. 1e). Este intervalo de coquinas constituye una excelente guía estratigráfica regional y fue reconocido en toda la Cordillera Oriental e incluso, en las Sierras Subandinas (Moya, 1998, 2008).

Los dos ciclos de inundación-somerización del tramo inferior de la Formación Floresta, a través de los que se registra la Zona de Anisograptus en la sierra de Mojotoro, también fueron reconocidos en la Formación Saladillo expuesta en el Angosto del Moreno (Fig. 1c). En ambas áreas, el ciclo más antiguo contiene una rica asociación de trilobites (Moya \& Monteros, 2000; Moya et al., 2003; Aris \& Malanca, 2005), entre cuyos integrantes se destaca la asociación de Apatokephalus exiguusConophrys sulcata, propuesta por Monteros (2005) para identificar la biozona de trilobites homónima. Esta biozona reemplaza al informal intervalo de transición del tramo inferior de la Formación Saladillo (sensu Moya et al., 2003), en el que coexisten especies de trilobites típi-

Figura 4. Dibujos de línea de especímenes de Anisograptus mojotorensis sp. nov. mostrando distintos aspectos conservacionales. 139/795 (5, 6, 7, 8, 9, 10, 11, 12), Villa Floresta. a (5), b (6), d (8): Especímenes juveniles y maduros conservados lateralmente, mostrando los tres estipes de primer orden. c (7), e (9), f (10), g (12), h (11): Especímenes juveniles y maduros preservados discoidalmente, mostrando un aparente aspecto cuadrirradiado. a: Espécimen con biteca sicular. c, d, e y h: Especímenes con algunas bitecas conservadas. Escala de las barras $1 \mathrm{~mm}$.

Line drawings of Anisograptus mojotorensis sp. nov. specimens showing different preservation aspects. 139/795 (5, 6, 7, 8, 9, 10, 11, 12), Villa Floresta. $\boldsymbol{a}(5), \boldsymbol{b}(6), \boldsymbol{d}(8)$ : Juvenile and mature specimens laterally preserved showing the three first order stipes. $\boldsymbol{c}$ (7), $\boldsymbol{e}$ (9), $\boldsymbol{f}(10), \boldsymbol{g}(12), \boldsymbol{h}$ (11): Juvenile and mature specimens discoidally preserved, showing an apparent quadriradiate aspect. $\boldsymbol{a}$ : Specimen with sicular bitheca. $\boldsymbol{c}, \boldsymbol{d}, \boldsymbol{e} y \boldsymbol{h}$ : Specimens with some preserved bithecae. Bar scale $1 \mathrm{~mm}$. 

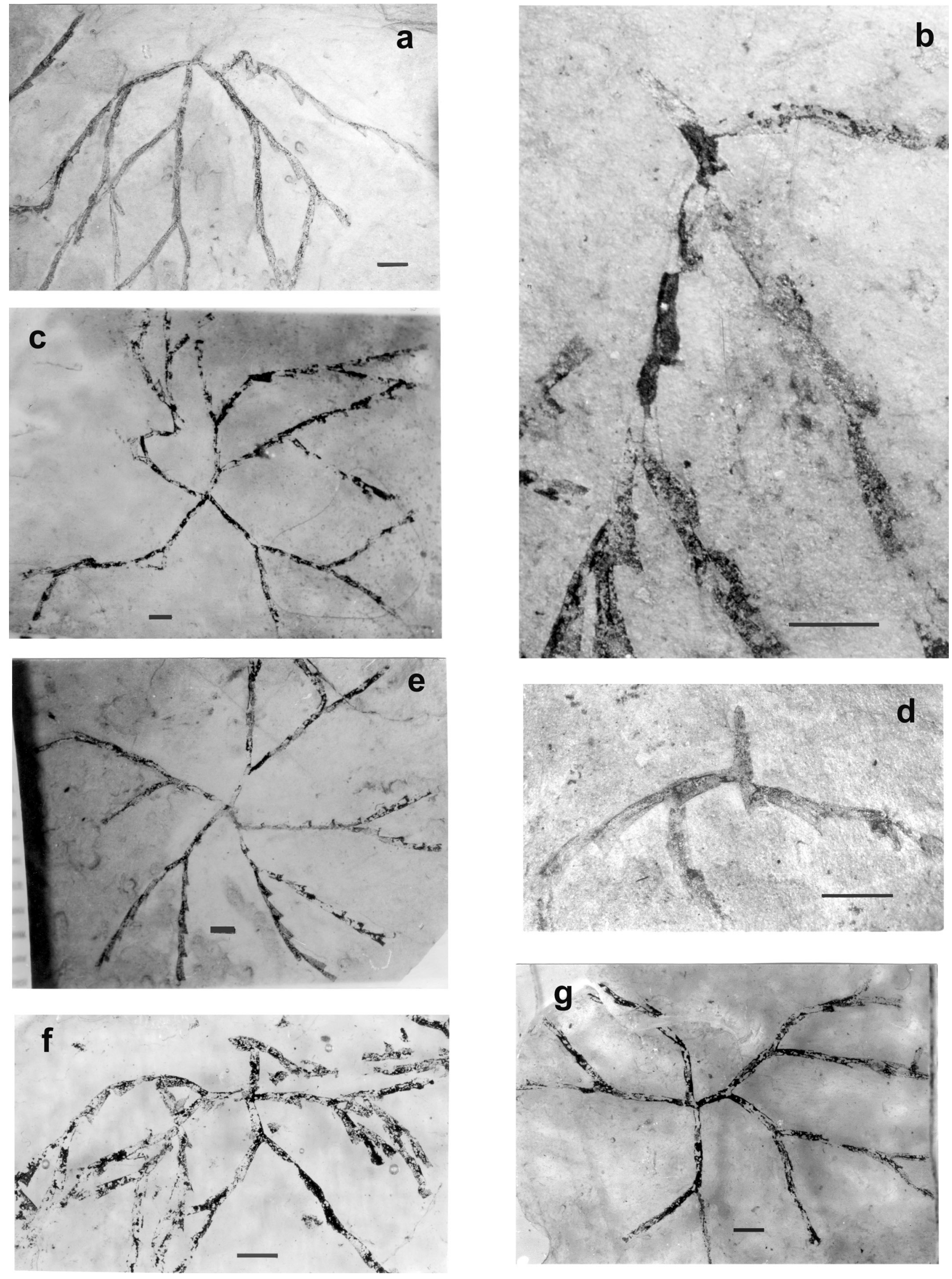
cas de la Zona de Parabolina (Neoparabolina) frequens argentina, de la Zona de $K$. meridionalis o de ambas, aunque es notable la ausencia de las especies nominales de las biozonas antedichas.

En resumen, la Zona de Apatokephalus exiguus-Conophrys sulcata se desarrolla en posición estratigráfica similar en la sierra de Mojotoro y en el Angosto del Moreno, extendiéndose a través del primer ciclo de inundación-somerización con el que se inician las formaciones Floresta y Saladillo, lo que permite establecer una aceptable correlación del intervalo de este ciclo en ambas áreas. La principal diferencia en el contenido paleontológico de dicho intervalo, es la falta de registro que hasta ahora se tiene de $A$. mojotorensis en el Angosto del Moreno, donde sólo se encontró $A$. matanensis acompañada por subespecies de Rhabdinopora flabelliformis (Moya et al., 1998, 2003; Ortega \& Albanesi, 2005), aún no registradas en la Zona de Anisograptus de la sierra de Mojotoro.

Obviamente, la falta de registro de $A$. mojotorensis en el Angosto del Moreno, puede obedecer a contingencias de muestreo; sin embargo, es importante señalar que la sucesión en la que allí se desarrolla la Zona de Apatokephalus exiguus-Conophrys sulcata, corresponde a un paleoambiente más somero (transición plataforma interna-plataforma externa proximal), que el desarrollado en la sierra de Mojotoro (plataforma externa intermedia a distal). En consecuencia, es probable que la aparente ausencia de $A$. mojotorensis en el Angosto del Moreno, sea una falta real de su registro, en respuesta a condiciones paleoambientales poco favorables para la especie. Sin embargo, es probable también que la falta de registro de $A$. mojotorensis en el Angosto del Moreno, responda a que el lapso vital de la especie, coincida con el hiato de la discontinuidad que separa las areniscas de la Formación Cardonal, de las pelitas de la base de la Formación Saladillo (fide Buatois et al., 2003; Moya et al., 2003). Si se acepta esta última alternativa, debiera admitirse también, la probabilidad que la aparición del desarrollo pseudo-cuadrirradiado que caracteriza a $A$. mojotorensis, constituya un bioevento previo a la aparición del definido desarrollo trirradiado de $A$. matanensis, tal como se presenta en la sierra de Mojotoro; este postulado reforzaría la hipótesis sobre el origen de Anisograptus a partir de Staurograptus, como fuera propuesto por Maletz (1992).

En otro orden, Cooper et al. (1998) y Cooper (1999) señalan que la aparición de Anisograptus ocurre en los estadios tardíos de la Zona de Iapetognathus y perdura dentro de la Zona de Cordylodus angulatus, hasta la aparición de los primeros anisográptidos birradiados. En el norte argentino, la Zona de Iapetognathus (con I. fluctivagus) fue reconocida en la Sierra de Cajas (Albanesi et al., 2010), en tanto que la Zona de Cordylodus angulatus fue reconocida en: Sierra de Cajas (Rao \& Hünicken, 1995), Angosto del Moreno (Moya et al., 2003), Angosto de la Quesera (Aceñolaza et al., 2003) y en las áreas de Purmamarca, Alfarcito y Lampazar-Pascha-Incahuasi (Ortega \& Albanesi, 2002) (Fig. 1c). Según la información contenida en la bibliografía precedente, las coquinas con $K$. meridionalis se habrían desarrollado dentro de la Zona de Cordylodus angulatus.

En particular, en el Angosto del Moreno, la Zona de Cordylodus angulatus fue registrada en la parte superior de la Zona de Anisograptus, a través del segundo ciclo de inundación-somerización de la Formación Saladillo; es decir, en el ciclo que culmina con las coquinas con $K$. meridionalis. En esta área, al igual que en la sierra de Mojotoro (donde aún no fue documentada la Zona de Cordylodus angulatus), el intervalo de coquinas con $K$. meridionalis, subyace a lutitas en las que $A$. matanensis acompaña a los primeros anisográptidos birradiados (Monteros \& Moya, 2005).

En síntesis, los datos hasta ahora disponibles vinculan los primeros registros de la Zona de Cordylodus angulatus con la parte alta de la Zona de Anisograptus, intervalo que sería el correlato de la Subzona de A. matanensis de la sierra de Mojotoro. Por tanto, se considera que la Subzona de $A$. mojotorensis en la sierra de Mojotoro, se correspondería con el estadio más tardío de la Zona de $I a$ petognathus, pudiendo alcanzar el lapso más temprano de la Zona de $C$. angulatus.

En base a los considerandos previos, se establece una correlación general de la Subzona de A. mojotorensis con el intervalo más temprano de la Biozona global de $A$. $m a$ tanensis señalada por Cooper (1999). Es probable que este correlato se corresponda con los intervalos que en China y Australia, contienen A. guangdongensis y A. delicatulus, especies que guardan estrechas afinidades con $A$. mojotorensis. En aquellas regiones, los anisográptidos pseudocuadrirradiados integran asociaciones localmente identificadas en la Zona de Staurograptus-Anisograptus, Subzona de Staurograptus dichotomus del sur de China (Yu et al., 1984), en la Zona de Staurograptus-Anisograptus del sudeste de China (Li et al., 1985; Xiao \& Chen, 1993), en

Figura 5. Especímenes de Anisograptus mojotorensis sp. nov. mostrando diferentes aspectos conservacionales. 139/795 (5, 6, 8, 9 , 10, 13, 14), Villa Floresta. a (8): Rabdosoma maduro preservado lateralmente. b (5), d (6): Especímenes juveniles preservados lateralmente, mostrando estipes de primero y segundo orden. c (10), e (9), f (13), g (14): Rabdosomas maduros preservados discoidalmente, mostrando aspecto pseudo-cuadrirradiado. Escala de las barras $1 \mathrm{~mm}$. Specimens of Anisograptus mojotorensis sp. nov. showing different preservation aspects. 139/795 (5, 6, 8, 9, 10, 13, 14), Villa Floresta. a (8): Mature rhabdosome laterally preserved. $\boldsymbol{b}$ (5), d (6): Juvenile specimens laterally preserved, showing first and second order stipes. $\boldsymbol{c}$ (10), $\boldsymbol{e}$ (9), $\boldsymbol{f}$ (13), $\boldsymbol{g}$ (14): Mature rhabdosomes discoidally preserved, showing pseudoquadriradiate aspect. Bar scale $1 \mathrm{~mm}$. 
la Zona de Anisograptus o de A. matanensis del nordeste de China (Wang \& Erdtmann, 1986; Feng \& Erdtmann, 1999) y en la Zona de Anisograptus-Rhabdinopora scitula de Victoria, Australia (Vandenberg \& Cooper, 1992). A esta última se vincularían los niveles con $A$. cf. delicatulus de Nueva Zelanda, los que se registran en la parte baja de la Biozona de C. angulatus (Wright et al., 1994).

\section{AGRADECIMIENTOS}

A los doctores Juan Carlos Gutiérrez-Marco y Gladys Carmen Ortega, por sus atinados comentarios y cuidadosa revisión. Al Consejo de Investigación de la Universidad Nacional de Salta, que nos proporcionó el apoyo económico para el desarrollo de las tareas, en el marco de los Proyectos 1582, 1682 y 1963.

\section{BIBLIOGRAFIA}

Aceñolaza, F.G. \& Durand, F. 1984. Observaciones sobre la fauna graptolítica tremadociana del Famatina, provincia de La Rioja. Actas del IX Congreso Geológico Argentino, Bariloche, 4, 267-276.

Aceñolaza, G.F., Milana, J.P., Heredia, S. \& Simoes, M. 2003. Stratigraphical and biostratigraphical framework of the Angosto de la Quesera conglomerate complex (Cordillera Oriental de Salta): An incised valley system in the Tremadocian of NW Argentina. In: Ordovician from the Andes (Eds. G.L. Albanesi, M.S. Beresi \& S.H. Peralta). Serie Correlación Geológica, 17, 365-370.

Albanesi, G.L., Monaldi, C.R., Ortega, G. \& Trotter, J.A. 2007. The Capillas Formation (Late Darriwilian) of the Subandean Ranges, Northwestern Argentina: Age, Correlation and environmental constraints. Acta Paleontologica Sinica, 46 (Supl.), 9-15.

Albanesi G.L., Ortega, G., Zeballo, F.J. \& Pacheco, F.E. 2010. The Cambrian-Ordovician boundary in South America: High resolution biostratigraphy, global correlation and paleoenvironments. Third International Palaeontological Congress, London, Abstracts, 67.

Aparicio González, P.A., Moya, M.C. \& Impiccini, A. 2010. Estratigrafía de las rocas metasedimentarias (Neoproterozoico-Cámbrico) de la sierra de Mojotoro, Cordillera Oriental argentina. Latin American Journal of Sedimentology and Basin Analysis, 17, 65-83.

Aris, J. \& Malanca, S. 2005. Asociaciones graptolíticas de la Formación Floresta (Tremadociano) en el sector medio de la sierra de Mojotoro, Salta, Argentina. Actas del XVI Congreso Geológico Argentino, La Plata, 3, 325-332.

Bronn, H. G. 1849. Index Palaeontologicus. Handbuch einer Geschichte der Nature 3, Stuttgart. A. Nomenclator palaeontologicus, 1328 pp. B. Enumerator palaeontologicus, 1106 pp.

Buatois, L.A., Moya, M.C., Mángano, M.G., Albanesi, G.L. \& Malanca, S. 2003. Paleoenvironmental and sequence stratigraphic framework of the Cambrian-Ordovician transition in the Angosto del Moreno area, Northwest Argentina. In: Ordovician from the Andes (Eds. G.L. Albanesi, M.S. Beresi \& S.H. Peralta). Serie Correlación Geológica, 17, 397-401.

Bulman, O.M.B. 1941. Some dichograptids of the Tremadocian and Lower Ordovician. Annals and Magazine of Natural History, 11 (7), 100-121.

Bulman, O.M.B. 1950. Graptolites from the Dictyonema Shales of Quebec. Quaterly Journal of the Geological Society of London, 106, 63-99.

Bulman, O.M.B. 1954. The graptolite fauna of the Dictyonema Shales of the Oslo region. Norsk Geologisk Tidsskrift, 33, 1-40.

Carlorosi, J., Heredia, S., Sarmiento, G.N. \& Moya, M.C. 2011. Reworked conodonts in the Upper Ordovician Santa Gertrudis Formation (Salta, Argentina). In: Ordovician of the World (eds. J.C. Gutiérrez-Marco, I. Rábano \& D. García Bellido). Cuadernos del Museo Geominero de España, 14, 83-87.

Chen X. 1985. Earliest Ordovician graptolites from western Zhejian, China and their faunal distribution. Journal of Paleontology, 59, 495-510.

Cooper, R.A. 1999. Ecostratigraphy, zonation and global correlation of earliest Ordovician planktic graptolites. Lethaia, 32, 1-16.

Cooper, R.A. \& Stewart, I.R. 1979. The Tremadoc graptolite sequence of Lancefield, Victoria. Palaeontology, 22, 767-797.

Cooper, R.A., Maletz, J., Wang, H. \& Erdtmann, B.-D. 1998. Taxonomy and evolution of earliest Ordovician graptoloids. Norsk Geologisk Tidsskrift, 78, 3-32.

Elles, G.L. 1922. The Graptolite Faunas of the British Isles. Proceedings of the Geological Association, 33, 168-200.

Emmons, E. 1855. American Geology. Sprague, 1 (1), 194 pp.

Erdtmann, B.-D. \& Botsford, J. W. 1986. A new early Tremadoc (La1) graptolite faunule from western Newfoundland: its Australian affinity and biofacies relations. Canadian Journal of Earth Siences, 23, 766-773.

Feng, H. \& Erdtmann, B.-D. 1999. The early Tremadoc graptolite sequence in the Wuning area, South China and its international correlation. In: Acta Universitatis Carolinae (Eds. P. Kraft \& O. Fatka). Geologica, 43, 21-28.

Fortey, R.A. \& Cooper, R.A. 1986. A phylogenetic classification of the graptoloids. Palaeontology, 29, 631-654.

Gutiérrez Marco, J.C. \& Esteban, S.B., 2005. Graptolitos del Tremadocience (Ordovícico Inferior) de la Formación Volcancito, Sistema de Famatina, (La Rioja, Argentina). Revista Española de Paleontología, 20, 65-118.

Harrington, H.J. 1957. Ordovician Formations of Argentina. In: Ordovician Trilobites of Argentina (H.J. Harrington \& A.F. Leanza). Departament of Geology, University of Kansas, Special Publication, 1, 1-59.

Harris, W.J. \& Keble, R.A. 1928. The Staurograptus bed of Victoria. Proccedings of the Royal Society of Victoria, 40, 91-95.

Hopkinson, J. \& Lapworth, Ch. 1875. Descriptions of the graptolites of the Arenig and Llandeilo rocks of St. 
David's. Quarter Journal of Geological Society of London, 31, 631-672.

Li J., Ge M. \& Chen X. 1985. Xinchangian (Early Ordovician) anisograptid fauna from Taishan, Guangdong. Palaeontologia Cathayana, 2, 102-117.

Lin, Y.-k., 1981. New materials of graptodendroids with special reference to the classifications of graptodendroids. Bulletin of the Nanjing Institute of Geology and Palaeontology, Academia Sinica, 3, 241-262.

Malanca, S. 1996. Morfología y ontogenia de un nuevo shumardiidae (Trilobita) del Tremadociano de la sierra de Mojotoro, Salta, Argentina. Memorias del XII Congreso Geológico de Bolivia, Tarija, 1, 391-399.

Maletz, J. 1992. The proximal development in anisograptids (Graptolidea, Anisograptidae). Paläontologische Zeitschrift, 66, 297-309.

Monteros, J.A. 1999. Anisograptus delicatulus Cooper \& Stewart en la sierra de Mojotoro, Cordillera Oriental argentina. Implicancias bioestratigráficas. Actas del XIV Congreso Geológico Argentino, Salta, 1, 50-51.

Monteros, J.A. 2005. Las graptofaunas del Ordovícico Inferior en la Sierra de Mojotoro, Cordillera Oriental argentina. Tesis doctoral, Universidad Nacional de Salta, Facultad de Ciencias Naturales, 197 pp. (inédita).

Monteros, J.A. \& Moya, M.C. 2005. La Zona de Adelograptus (Tremadociano) en el Tremadociano de la Cordillera Oriental argentina. Actas del XVI Congreso Geológico Argentino, La Plata, 3, 399-406.

Monteros, J.A. \& Moya, M.C. 2006. Las biozonas de graptolitos en el Tremadociano de la sierra de Mojotoro, Cordillera Oriental argentina. Acta de Resúmenes del IX Congreso Argentino de Paleontología y Bioestratigrafía, Córdoba, 160.

Monteros, J.A., Moya, M.C. \& Domínguez, R. 2011. Nueva técnica para aislar graptolitos. Acta de Resúmenes del XVIII Congreso Geológico Argentino. Neuquén, 1490-1491.

Moya, M.C. 1998. El Paleozoico inferior en la sierra de Mojotoro, Salta-Jujuy. Revista de la Asociación Geológica Argentina, 53, 219-238.

Moya, M.C. 2008. El Paleozoico Inferior en el Noroeste Argentino. Evidencias, Incógnitas, Propuestas para la Discusión. In: Geología y Recursos Naturales de la Provincia de Jujuy (Eds. B. Coira \& E.O. Zappettini). Relatorio del XVII Congreso Geológico Argentino, San Salvador de Jujuy, 74-84.

Moya, M.C. \& Monteros, J.A. 2000. El Angosto del Moreno (Cordillera Oriental argentina), un área clave para analizar el límite Cámbrico-Ordovícico y la discordancia Iruya. Memorias del XIV Congreso Geológico Boliviano, La $\mathrm{Paz}, 142-147$.

Moya, M.C. \& Monteros, J.M. 2011. The Tremadocian Deposits of the Argentinian Eastern Cordillera: A Scandinavian Signal in the Central Andes. In: Ordovician of the World (eds. J.C. Gutiérrez-Marco, I. Rábano \& D. García Bellido). Cuadernos del Museo Geominero de España, 14, 379-390.
Moya, M.C., Malanca, S., Monteros, J.A. \& Cuerda, A. 1994. Bioestratigrafía del Ordovícico Inferior en la Cordillera Oriental argentina basada en graptolitos. Revista Española de Paleontología, 9, 91-104.

Moya, M.C., Monteros, J.A. \& Monaldi, C.R. 1998. Graptolite dating of Lower Ordovician unconformity in the Argentinian Andes. Temas Gelógico-Mineros ITGE, 23, 227-230.

Moya, M.C., Malanca, S., Monteros, J.A., Albanesi, G.L., Ortega, G. \& Buatois, L.A. 2003. Late Cambrian -Tremadocian faunas and events from Angosto del Moreno Section, Eastern Cordillera, Argentina. In: Ordovician from the Andes (Eds. G.L. Albanesi, M.S. Beresi \& S.H. Peralta). Serie Correlación Geológica, 17, 439-444.

Ortega, G. \& Albanesi, G.L. 2002. Bioestratigrafía de graptolitos y conodontes del Tremadociano tardío de la Cordillera Oriental argentina. Actas del XV Congreso Geológico Argentino, El Calafate, 1, 542-547.

Ortega, G. \& Albanesi, G.L. 2005. Tremadocian graptoliteconodont biostratigraphy of the South American Gondwana margin (Eastern Cordillera, NW Argentina). Geologica Acta, 3, 355-371.

Rao, R.I. \& Hunicken, M.A.1995. Conodont biostratigraphy of the Cambrian-Ordovician boundary in northwestern Argentina. In: Ordovician Odyssey (Eds. J.D. Cooper, M.L. Droser \& S.C. Finney) Pacific Section, Society for Sedimentary Geology, Fullerton, book 77, 125-128.

Ruedemann, R. 1937. A New North American graptolite faunule. American Journal Sciences, 33, 57-62.

Sour, F. \& Buitrón, B.E. 1987. Los graptolitos del Tremadociano de Ixtaltepec, Oaxaca. Consideraciones sobre el límite Cámbrico-Ordovícico en la región. Revista de la Sociedad Mexicana de Paleontología, 1, 380-395.

Turner, J.C.M. 1960. Faunas graptolíticas de América del Sur. Revista de la Asociación Geológica Argentina, 14, 5-180.

Vandenberg, A.H.M. \& Cooper, R.A. 1992. The Ordovician graptolite sequence of Australasia. Alcheringa, 16, 33-85.

Wang, X.-f. \& Erdtmann, B.-D. 1986. The Early Ordovician Graptolite Sequence of Hunjiang, Jilin Province, China. Acta Geologica Sinica, 60, 13-22.

Wang, X.-f., Liu, Y.-r. \& Zhou, G.-q. 1979. Graptolites from the Early Ordovician Xinchang Formation in Taishan of Guangdong. Acta Palaeontologica Sinica, 18, 493-504.

Wright, A.J., Cooper, R.A. \& Simes, J.E. 1994. Cambrian and Ordovician faunas and stratigraphy, Mt Patriarch, New Zealand. New Zealand Journal of Geology and Geophysics, 37, 437-476.

Xiao, C.-x. \& Chen, H.-y. 1993. Graptolites from Early Ordovician Maoping Formation of Chongyi, Jiangxi. Acta Palaeontologica Sinica, 32, 355-370.

Yu, J.-h., Liu, H.-b. \& Fang Y.-t. 1984. Anisograptidae of the Xinchangian Age (Early Ordovician) from the Xiushui Drainage Basin, Jiangxi. Acta Paleontologica Sinica, 23, 532-546.

Manuscrito recibido: 11 de octubre, 2010 Manuscrito aceptado: 25 de julio, 2011 